\title{
Oxidized LDL Receptor 1 gene polymorphism in patients with Metabolic Syndrome
}

\author{
Vincenzo O. Palmieri ${ }^{*}$, Brigida Coppola ${ }^{\dagger}$, Ignazio Grattagliano ${ }^{*}$, Valentina Casieri $^{\dagger}$, Giovanna Cardinale $^{*}$, \\ Piero Portincasa ${ }^{*}$, Giuseppe Palasciano $^{*}$ and Francesca Di Serio ${ }^{\dagger}$ \\ *Department of Biomedical Sciences and Human Oncology, Clinica Medica 'A. Murri', University of Bari, Bari, Italy, \\ ${ }^{\dagger}$ Department of Clinical Pathology I, Policlinico University Hospital, Bari, Italy
}

\begin{abstract}
Aims The lectin-like oxidized low-density lipoprotein receptor-1 (LOX-1), encoded by the OLR1 gene, has been implicated in the pathogenesis of atherosclerosis. We therefore evaluated the genotyping of OLR1 gene in a sample of 55 patients with Metabolic Syndrome, a clinical condition characterized by a high cardiovascular risk.
\end{abstract}

Methods and Patients The genotyping of the LOX-1 was performed by polymerase chain reaction (PCR) analysis of the IVS4-14 A>G OLR1 polymorphism embedded within the OLR1 Linkage Disequilibrium block. Patients were assessed for routine serum parameters, microalbuminuria, insulin resistance (HOMA) and oxidative stress (thiobarbituric acid reactive substances, TBARs and thioredoxin).

Results The allele or genotype distribution of the OLR1 IVS4-14 A>G was not statistically different between MS and controls subjects. A positive association was found between IVS4-14 GG genotype, microalbuminuria and fasting glycaemia as well as a higher frequency of type 2 diabetes, elevated microalbuminuria, fasting serum glucose and HOMA index in the same subjects. Thioredoxin values were higher in patients with MS but did not differ in relation to OLR1 IVS4-14 A>G genotype. The TBARs/Cholesterol ratio was higher in MS both in IVS4-14 GG and in IVS4-14 AG.

Conclusion IVS4-14 GG genotype seems to be related to glucose metabolism disturbance, elevated insulin level and lipid peroxidation in patients with MS.

Keywords Insulin resistance, LOX-1 polymorphism, Metabolic Syndrome, microalbuminuria, Thiobarbituric acid, Thioredoxin.

Eur J Clin Invest 2013; 43 (1): 41-48

\section{Introduction}

The Metabolic Syndrome (MS) is a clinical disorder with a high prevalence in Western adult population and characterized by the clustering of several metabolic factors [1], that is, abdominal obesity, high plasma triglycerides levels, low HDL cholesterol, arterial hypertension $(\mathrm{AH})$ and fasting hyperglycaemia, and is associated with high mortality rate and major cardiovascular events $[2,3]$.

The factors that characterize the MS are also associated with the atherosclerotic process, in which an important role is played by the interaction between oxidized low-density lipoproteins (oxLDLs) and their major receptor named lectin-like receptor for oxidized low-density lipoprotein (LOX-1). This interaction induces the activation of a complex pathway with final effects represented by the endothelial disfunction/apoptosis and change in vascular biology and atherosclerotic plaque formation. [4-6]. LOX-1 is expressed in endothelial cells, macrophages, smooth muscle cells, platelets and is over-expressed in human and animal atherosclerotic lesions in vivo $[7,8]$ and in the ischaemic-reperfused rat myocardium [9]. LOX-1 is upregulated not only by oxLDLs but also by other mediators of atherosclerosis such as angiotensin II (Ang II), cytokines, sheer stress and advanced glycation end-products (AGE) and is dynamically upregulated by pro-atherosclerotic conditions such as hypertension, dyslipidaemia and diabetes [8,10-12]. LOX-1 is encoded by OLR1 gene mapped on human chromosome 12p12-3-13·1 [13], a region that, by linkage analysis, has been found to be frequently associated with cardiovascular diseases. Gene association studies have identified single nucleotide polymorphisms (SNPs) within the OLR1 gene that are associated with coronary atherosclerosis and acute myocardial infarction 
[14,15]. In particular, six SNPs embedded within a linkage disequilibrium (LD) block, spanning from intron 4 up 3'Untranslated Region (UTR) of the OLR1 gene, showed a positive association with acute myocardial infarction [14]. Moreover, recent studies have shown that LD SNPs of OLR1 gene regulate the expression of a new functional splicing isoform of LOX-1 receptor named LOXINA which has a negative association with myocardial infarction, suggesting a protective role of LOXINA in cardiovascular events [16]. Homozygote subjects for the 'not cardiovascular risk' haplotype, included in LD block, have a positive LOXINA/LOX-1 ratio compared with homozygous for the 'cardiovascular risk' haplotype [16].These observations suggest that the determination of OLR1 genotype may be important for the prediction of cardiovascular diseases, although opposed results have been reported [17-19].

To our knowledge, no data exist on genotyping of LOX-1 gene in patients with the MS. This may have important implications not only for targeting each specific features of MS but also for assessing endothelial disfunction in early atherosclerotic process.

It has also been shown that oxidative stress may have a central pathogenic role in MS as it potentially explains the appearance of all risk factors and supports the clinical manifestations. In fact, patients with MS exhibit activation of biochemical pathways leading to increased delivery of reactive oxygen species, decreased antioxidant protection and increased lipid peroxidation. The described associations between increased abdominal fat storage, liver steatosis and systemic oxidative stress, the diminished concentration of nitric oxide derivatives and antioxidant vitamins and the endothelial oxidative damages observed in subjects with the MS definitively support oxidative stress as the common second-level event in a unifying pathogenic view [1]. For these reasons, it is reasonable to investigate the genotype of LOX-1 also in relation to the patterns of oxidative response in patients with the MS.

The aim of our study is therefore to evaluate the distribution of IVS4-14 A>G polymorphism, enclosed in the LOX-1 LD block, in a sample of patients with the MS and to establish which component of the MS is more likely related to the risk genotype.

\section{Material and methods}

The OLR1 genotyping analysis was performed with 'Loxin Test $^{\circledR}{ }^{\circledR}$ (Technogenetics, Milan, Italy). This kit allows the identification of IVS4-14 A>G polymorphism, embedded within the OLR1 LD block, by polymerase chain reaction (PCR) utilizing allele-specific LNA (Locked Nucleic Acid) primers able to identify the single-nucleotide mismatch $\mathrm{A} \rightarrow \mathrm{G}$. The kit supplies reagents and enzymes for the specific amplification of a $208 \mathrm{bp}$ region of OLR1 gene, containing the $A>G$ polymorphism, and a
257 bp region as PCR internal control. Each DNA sample from EDTA peripheral blood is amplified separately with two different master mix: the OLR1 wild type (WT) mix is able to detect the presence of A allele (low cardiovascular risk), while the OLR1 mutation type MT mix is specific for G allele (high cardiovascular risk) [20]. Homozygous AA and GG DNA samples are amplified only with OLR1 WT and OLR1 MT mix, respectively, while heterozygous AG DNA sample is amplified using both OLR1 WT and MT mix. Positive control sample for AA and GG genotypes, enclosed in the kit, were performed.

Consecutive 55 patients with the MS according to ATP-III criteria [21] were enrolled. Each patient was evaluated for absolute Cardiovascular Risk by applying the criteria established by the PROCAM project [22]. This was the patients' first diagnosis of MS. Exclusion criteria were the following: age below 18 and over 70 years, type 1 diabetes, maturity-onset diabetes, secondary diabetes or secondary hypertension diabetic complications, major systemic associated diseases (cardiac, respiratory, renal or hepatic failure), liver cirrhosis, recent acute severe diseases that could affect the expression of inflammatory and oxidative stress markers (fever, infective diseases, acute myocardial infarction, ischaemic or haemorrhagic cerebro-vascular events within the past 30 days, acute arterial occlusion, deep venous thrombosis), alcohol abuse, smoking habit, pregnant or breastfeeding women, current treatment with systemic corticosteroids, presence or history of cancer within the past 5 years. Control subjects were represented by 39 individuals not affected by MS and that did not meet the above reported exclusion criteria. Patients and control subjects were taking any vasoactive medication, lipid-lowering agents, vitamins or supplements and were not going to any diet or physical activity programme. Any significant difference was revealed between patients and control subjects for dietetic and physical activity habit during the last 3 months before entering the study. All subjects underwent to clinical examination, evaluation of routine serum parameters, microalbuminuria, insulin resistance (calculated by the HOMA formula), carotid ultrasonography to assess the common carotid intima-media thickness (IMT;

Fig. 1), blood tests for oxidative stress (thiobarbituric acid reactive substances (TBARs) and thioredoxin). TBARs and thioredoxin were measured as previously described [23,24]. Briefly, thiobarbituric acid reactive substances (TBARs) levels were determined spectrophotometrically (532 nm); thioredoxin levels were quantitated by a standardized ELISA method in plasma and liver homogenates (type 1) and in mitochondria (type 2). The procedure followed the manufacturer's instructions (Histo-line Laboratories S.r.l., Milan, Italy); samples were located in microwells previously coated with a polyclonal antibody (LF-PA0002) and successively with a primary (LF-MA0077) and a secondary HRP-conjugated antimouse 


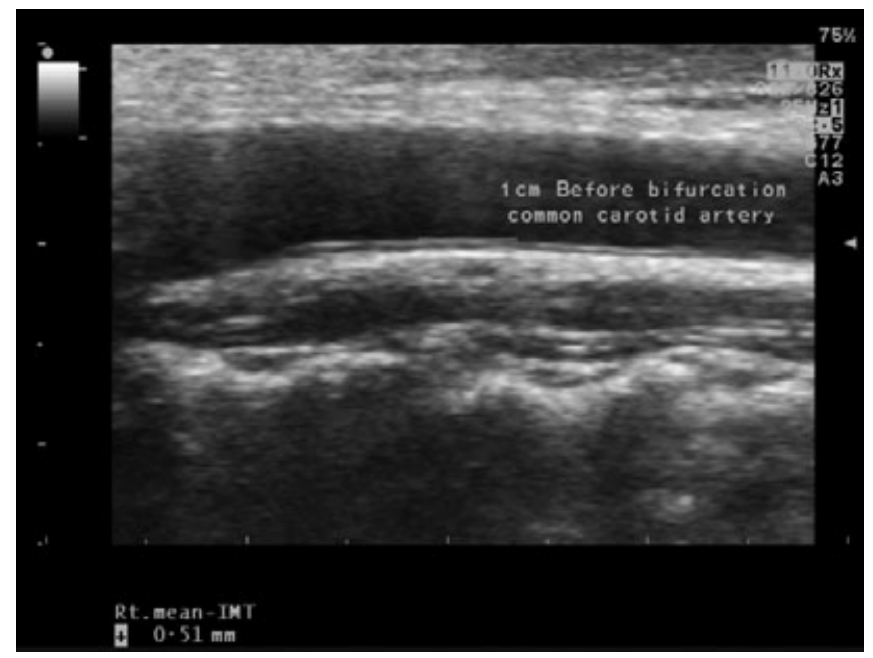

Figure 1 The intima-media thickness (IMT) measurement of the far wall of the common carotid artery at $1 \mathrm{~cm}$ before the carotid bifurcation.

antibody (81-6720). After addition of a chromogenic system, the reaction was stopped and absorbance read at $492 \mathrm{~nm}$.

All the other parameters were measured using routine automated assay methods after an overnight fast written consent was obtained from all participants. The study was approved by the Ethical Committee of the Medical Faculty at Bari University.

Descriptive statistics, including means, SD (or, when specified, SE), ranges and percentages, were used to characterize the study subjects. Because of lacking normal distribution, the Mann-Whitney rank-sum test was used to make comparisons. Differences between proportions were tested by chi-square. To compare the differences between groups, one-way analysis of variance was performed with Kruskal-Wallis multiple-comparison Z-value test (Dunn's Test) followed by Mann-Whitney $U$ or Wilcoxon rank-sum Test. To address the relationship between variables, Spearman rank correlations were performed. Calculations were performed with the NCSS 2007 statistical software. $P<0.05$ was considered statistically significant. Reporting of the study conforms to STREGA along with references to STREGA and the broader EQUATOR guidelines [25].

\section{Results}

The comparison of clinical and laboratory parameters allowed a clear differentiation of subjects with and without MS as shown in Table 1. In Table 2, the genotype distribution and allele frequencies for the OLR1 IVS4-14 A>G polymorphism observed in patients with MS is reported. Allele frequencies within each group were in Hardy-Weinberg equilibrium. No difference in genotype distribution and in the IVS4-14 G allele frequencies was found between MS patients and controls (G allele frequencies $55 \%$ vs. $53 \%, P=\mathrm{ns}$ ).

Nevertheless, the ranks Spearman correlation in whole population (MS and control subjects) showed that the strength of association between fasting hyperglycaemia $(>110 \mathrm{mg} / \mathrm{dL})$ and the microalbuminuria (>30 mg/dL) with the OLR1 IVS4-14 GG genotype was lightly significant $(r=0.287, P=0.005$ and $r=0 \cdot 200, P=0 \cdot 04$, respectively). By comparing the distribution of the main clinical characteristics in subjects with OLR1 IVS4-14 A>G genotypes, significant differences in the frequency of type 2 diabetes mellitus (DM) (GG $=60 \%, \mathrm{AG}=16 \%$, $\mathrm{AA}=16 \%, P=0.005)$, microalbuminuria $>30 \mathrm{mg} / \mathrm{dL}$ $(\mathrm{GG}=42 \%, \mathrm{AG}=17 \%, \mathrm{AA}=8 \%, P=0.03)$, fasting serum glucose $>110 \mathrm{mg} / \mathrm{dL}(\mathrm{GG}=68 \%, \mathrm{AG}=33 \% \mathrm{AA}=33 \%, P=0.005)$ and HOMA index $>2 \cdot 2(\mathrm{GG}=67 \%, \mathrm{AG}=36 \%, \mathrm{AA}=25 \%$, $P=0.04$ ) were found (Table 3 ).

The analysis of variance for the comparison between clinical characteristics of subjects with OLR1 IVS4-14 A>G genotypes showed that fasting serum glucose concentration, HOMA index, microalbuminuria and IMT were significantly higher in the group with GG genotype in comparison with AA and AG genotypes (Table 4). The values of Cardiovascular risk expressed according to the PROCAM model did not differ significantly between the three genotypes, although an increasing trend was noted from AA to GG genotypes. Patients with MS had significantly higher levels of serum thioredoxin compared to controls ( $2.24 \pm 0.49$ vs. $2.03 \pm 0.6 \mathrm{nM}, P<0.001)$. No difference in thioredoxin levels was noted by dividing study subjects per LOX genotype (AA 2.08 $\pm 0 \cdot 6$, AG 2.18 $\pm 0 \cdot 9$, GG $2.07 \pm 0.8 \mathrm{nM}, P=\mathrm{ns}$ ). A linear correlation was found between the serum thioredoxin levels and alanine transaminase (ALT) values $(r=0.812, P<0.0001)$. A significant difference in the circulating levels of lipid peroxidation products (expressed as TBARs/total cholesterol ratio) was noted between patients with or without MS (0.052 \pm 0.017 vs. $0.035 \pm 0.013 \mathrm{nM} / \mathrm{mM}$, $P<0.001)$. This difference was still evident by dividing patients with MS and controls by genotype: GG (0.053 \pm 0.015 vs. $0.036 \pm 0.005 \mathrm{nM} / \mathrm{mM} P<0.001)$, AG $(0.052 \pm 0.020$ vs. $0.035 \pm 0.015 \mathrm{nM} / \mathrm{mM}, P<0.001)$, AA $(0.048 \pm 0.013$ vs. $0.031 \pm 0.013 \mathrm{nM} / \mathrm{mM}, P<0.001)$. A significant inverse relationship was also noted between serum thioredoxin levels and TBARs/cholesterol ratio $(r=0.456 P<0 \cdot 001)$.

\section{Discussion}

In this study, the IVS4-14 A>G polymorphism of the OLR1 gene, which is in complete LD with 3'UTR-188 C>T described to be associated with AMI or CAD [14], was analysed in 55 patients with MS, a clinical condition with increased risk for 
Table 1 Demographic and clinical characteristics of study subjects [values are mean \pm SD or number of observation (\%)]

\begin{tabular}{|c|c|c|c|}
\hline & Metabolic Syndrome & Controls & $\boldsymbol{P}$ \\
\hline Subjects $(n)$ & 55 & 39 & - \\
\hline Age (years) & $53 \cdot 8 \pm 9 \cdot 6$ & $47 \cdot 8 \pm 12 \cdot 2$ & 0.007 \\
\hline Sex (male/female) & $34 / 21$ & $19 / 20$ & NS \\
\hline N. criteria for MS (ATP III, 2001) & $3 \cdot 2 \pm 0.8$ & $1 \cdot 1 \pm 0 \cdot 7$ & 0.00001 \\
\hline BMI $\left(\mathrm{kg} / \mathrm{m}^{2}\right)$ & $31 \cdot 6 \pm 4 \cdot 7$ & $26 \cdot 2 \pm 4 \cdot 7$ & 0.00001 \\
\hline Waist circumference $(\mathrm{cm})$ & $106 \cdot 4 \pm 9 \cdot 9$ & $96 \cdot 1 \pm 11 \cdot 0$ & 0.0001 \\
\hline Fasting plasmatic glucose (mg/dL) & $117 \cdot 7 \pm 38 \cdot 4$ & $97 \cdot 2 \pm 28 \cdot 9$ & 0.0001 \\
\hline Triglycerides (mg/dL) & $203 \cdot 5 \pm 187 \cdot 7$ & $92 \cdot 7 \pm 43 \cdot 5$ & 0.00001 \\
\hline HDL cholesterol (mg/dL) & $41 \cdot 5 \pm 9 \cdot 1$ & $52 \cdot 7 \pm 9 \cdot 9$ & 0.00001 \\
\hline Total cholesterol (mg/dL) & $207 \cdot 1 \pm 40 \cdot 6$ & $191 \cdot 3 \pm 41 \cdot 1$ & 0.03 \\
\hline LDL cholesterol (mg/dL) & $132 \cdot 1 \pm 34 \cdot 4$ & $119 \cdot 5 \pm 36 \cdot 7$ & 0.04 \\
\hline Protein $C$ reactive $(\mathrm{mg} / \mathrm{dL})$ & $0.56 \pm 0.51$ & $0.27 \pm 0.19$ & 0.002 \\
\hline Microalbuminuria (mg/dL) & $78 \cdot 8 \pm 219 \cdot 1$ & $14 \cdot 1 \pm 8 \cdot 2$ & 0.001 \\
\hline HOMA index & $3 \cdot 3 \pm 2 \cdot 7$ & $1 \cdot 5 \pm 1 \cdot 1$ & 0.0001 \\
\hline Intima-media thickness, IMT (cm) & $0.09 \pm 0.02$ & $0.08 \pm 0.02$ & 0.04 \\
\hline Cardiovascular Risk (PROCAM) & $12 \cdot 1 \pm 11 \cdot 1$ & $1 \cdot 8 \pm 1 \cdot 2$ & 0.001 \\
\hline Arterial hypertension & $48(87)$ & $10(26)$ & 0.00001 \\
\hline Fasting plasmatic glucose $>110 \mathrm{mg} / \mathrm{dL}$ & $30(55)$ & $8(21)$ & 0.001 \\
\hline HDL cholesterol ( $\mathrm{M}<40 \mathrm{mg} / \mathrm{dL} ; \mathrm{F}<50 \mathrm{mg} / \mathrm{dL})$ & $32(58)$ & $7(18)$ & 0.0001 \\
\hline Triglycerides $>150 \mathrm{mg} / \mathrm{dL}$ & $24(44)$ & $3(8)$ & 0.0002 \\
\hline Type 2 DM & $18(33)$ & $6(16)$ & 0.04 \\
\hline HOMA index $>2.2$ & $29(53)$ & $9(23)$ & 0.0008 \\
\hline $\mathrm{BMI}>30 \mathrm{~kg} / \mathrm{m}^{2}$ & $31(57)$ & $8(21)$ & 0.0006 \\
\hline Intima-media thickness, IMT $>0.1 \mathrm{~cm}$ & $24(44)$ & $7(18)$ & 0.05 \\
\hline
\end{tabular}

Table 2 Genotypes and allele frequencies for IVS4-14 A>G polymorphism in OLR1 gene in studied subjects

\begin{tabular}{cccc}
\hline & MS $(\boldsymbol{n}=55)$ & Controls $(\boldsymbol{n}=39)$ & $P$ \\
Genotypes, $n(\%)$ & & \\
AA & $7(13)$ & $27(13)$ \\
AG & $36(65)$ & $7(18)$ & NS \\
GG & $12(22)$ &
\end{tabular}

Alleles, $n(\%)$

$\begin{array}{lll}\text { A } & 50(45) & 37(47) \\ \text { G } & 60(55) & 41(53)\end{array}$

NS, not significant. cardiovascular events. Our data show that the distribution of the risk genotype IVS4-14 GG seems not to differ statistically between patients affected by MS and control subjects. Similarly, the no risk genotype IVS4-14 AA is not distributed in a different percentage between the two study groups. However, there is a positive association between the risk genotype and the frequency of hyperglicaemia $>110 \mathrm{mg} \%$ as well as of pathological value of microalbuminuria. Consistently with this observation, the frequency of patients with type $2 \mathrm{DM}$, microalbuminuria $>30 \mathrm{mg} / \mathrm{dL}$ and elevated levels of HOMA index, as well as the respective average values, are significantly increased in risk genotype compared to the no risk genotype patients. Furthermore, IMT values are higher in patients with risk genotype compared to both no risk and eterozygous genotype subjects. 
Table 3 Distribution of clinical characteristics according to IVS4-14 A>G genotypes in the whole population [ $n$ of observations (\%)]

\begin{tabular}{|c|c|c|c|c|}
\hline & GG ( $n=19)$ & AG $(n=63)$ & $\mathrm{AA}(n=12)$ & $\boldsymbol{P}$ \\
\hline Sex (male/female) & $10 / 9$ & $34 / 29$ & $9 / 3$ & NS \\
\hline Metabolic syndrome (ATP III, 2001) & $11(58)$ & $36(57)$ & 7 (58) & NS \\
\hline Arterial hypertension & $12(63)$ & $38(60)$ & $8(67)$ & NS \\
\hline HDL Cholesterol ( $\mathrm{M}<40 \mathrm{mg} / \mathrm{dL} ; \mathrm{F}<50 \mathrm{mg} / \mathrm{dL})$ & $9(47)$ & $25(40)$ & $5(42)$ & NS \\
\hline Triglycerides $>150 \mathrm{mg} / \mathrm{dL}$ & $8(42)$ & $17(27)$ & $2(17)$ & NS \\
\hline Type 2 DM & $12(60)$ & $10(16)$ & $2(16)$ & 0.005 \\
\hline Microalbuminuria $>30 \mathrm{mg} / \mathrm{dL}$ & $8(42)$ & $11(17)$ & $1(8)$ & 0.03 \\
\hline Fasting plasmatic glucose $>110 \mathrm{mg} / \mathrm{dL}$ & $13(68)$ & $21(33)$ & $4(33)$ & 0.005 \\
\hline HOMA index $>2.2$ & $12(67)$ & $23(36)$ & $3(25)$ & 0.04 \\
\hline Waist circumference $(\mathrm{M}>102 \mathrm{~cm} ; \mathrm{F}>88 \mathrm{~cm})$ & $11(58)$ & $42(67)$ & $8(67)$ & NS \\
\hline $\mathrm{BMI}>30 \mathrm{~kg} / \mathrm{m}^{2}$ & $9(47)$ & $26(41)$ & $4(33)$ & NS \\
\hline $\mathrm{IMT}>0.1 \mathrm{~cm}$ & $8(47)$ & $21(33)$ & $2(17)$ & NS \\
\hline
\end{tabular}

$M=$ males; $F=$ females

Table 4 Comparison between clinical characteristics in subjects with IVS4-14 A>G genotypes (values are mean \pm SE).

\begin{tabular}{|c|c|c|c|c|}
\hline & GG (n=19) & $\mathrm{AG}(n=63)$ & $\mathrm{AA}(n=12)$ & $\boldsymbol{P}$ \\
\hline Age & $58 \cdot 2 \pm 2 \cdot 6$ & $51.5 \pm 1 \cdot 4$ & $48 \cdot 3 \pm 3 \cdot 2$ & NS \\
\hline Cardiovascular risk (PROCAM) & $7 \cdot 8 \pm 3 \cdot 0$ & $8.9 \pm 1.7$ & $4 \cdot 8 \pm 3 \cdot 2$ & NS \\
\hline N. criteria for MS (ATP III, 2001) & $2 \cdot 8 \pm 0 \cdot 3$ & $2 \cdot 3 \pm 0 \cdot 2$ & $2 \cdot 2 \pm 0 \cdot 4$ & NS \\
\hline $\mathrm{BMI}\left(\mathrm{Kg} / \mathrm{m}^{2}\right)$ & $31 \cdot 0 \pm 1 \cdot 4$ & $29 \pm 0.8$ & $28 \cdot 5 \pm 1 \cdot 7$ & NS \\
\hline Waist circumference (cm) & $100 \cdot 6 \pm 2 \cdot 6$ & $103 \cdot 3 \pm 1 \cdot 5$ & $102 \cdot 5 \pm 3 \cdot 5$ & NS \\
\hline Systolic blood pressure $(\mathrm{mmHg})$ & $130 \cdot 8 \pm 3 \cdot 4$ & $135 \pm 1.9$ & $130 \pm 4 \cdot 3$ & NS \\
\hline Diastolic blood pressure $(\mathrm{mmHg})$ & $82 \cdot 6 \pm 2 \cdot 2$ & $85 \cdot 4 \pm 1 \cdot 2$ & $82 \cdot 5 \pm 2 \cdot 8$ & NS \\
\hline Fasting plasmatic glucose (mg/dL) & $134 \cdot 2 \pm 7 \cdot 8$ & $102 \cdot 1 \pm 4 \cdot 3$ & $105 \cdot 9 \pm 9 \cdot 8$ & $<0.01^{*}$ \\
\hline Serum insulin (pM) & $13 \cdot 2 \pm 1 \cdot 90$ & $10 \cdot 4 \pm 1 \cdot 1$ & $8 \cdot 3 \pm 2 \cdot 6$ & NS \\
\hline HOMA index & $3.7 \pm 0.5$ & $2 \cdot 3 \pm 0 \cdot 3$ & $1.9 \pm 0.7$ & $<0.04^{* *}$ \\
\hline Microalbuminuria (mg/dL) & $62 \cdot 4 \pm 41 \cdot 7$ & $56 \cdot 6 \pm 22 \cdot 2$ & $13 \cdot 7 \pm 51 \cdot 9$ & $<0.05^{* *}$ \\
\hline Triglycerides (mg/dL) & $206 \cdot 3 \pm 35 \cdot 5$ & $148 \cdot 8 \pm 19 \cdot 6$ & $122 \pm 44 \cdot 6$ & NS \\
\hline Total cholesterol $(\mathrm{mg} / \mathrm{dL})$ & $201 \pm 9 \cdot 6$ & $201 \cdot 2 \pm 5 \cdot 3$ & $195 \cdot 6 \pm 12 \cdot 0$ & NS \\
\hline HDL cholesterol (mg/dL) & $45 \cdot 6 \pm 2 \cdot 7$ & $47 \cdot 1 \pm 1 \cdot 4$ & $44 \cdot 2 \pm 3 \cdot 2$ & NS \\
\hline LDL cholesterol (mg/dL) & $126 \cdot 5 \pm 8 \cdot 8$ & $126 \cdot 4 \pm 4 \cdot 7$ & $127 \cdot 3 \pm 10 \cdot 4$ & NS \\
\hline $\mathrm{PCR}(\mathrm{mg} / \mathrm{dL})$ & $0.5 \pm 0.1$ & $0 \cdot 4 \pm 6 \cdot 1$ & $0.5 \pm 0.1$ & NS \\
\hline IMT (cm) & $0 \cdot 1 \pm 0 \cdot 03$ & $0 \cdot 13 \pm 0.02$ & $0.08 \pm 0.04$ & $<0.04^{* * *}$ \\
\hline
\end{tabular}

*, GG both vs. AA and AG; **, GG vs. AA; ***, AA both vs. GG and AG.

Provided that our patients with MS seems to have a cardiovascular diseases risk evaluated with PROCAM score higher than control subjects, the lack of a significant difference in the distribution of the OLR1 IVS4-14 A>G SNP between patients and controls seems to be in contrast with previous observations. In particular, Mango et al. [14] showed that subjects with 
the TT or CT genotype at OLR1 3’UTR polymorphism are at higher risk of developing acute myocardial infarction (AMI) (OR, 3.74), and Chen et al. [15] showed that common genetic variation in the LOX1 gene is associated with angiographic coronary artery disease (CAD) in women. Our observation do not demonstrate a different frequency distribution of OLR1 SNP detected and are rather in accord with subsequent observations carried out by two other research groups $[17,18]$, which have shown that the OLR1 SNPs genotype frequency distribution in CAD or AMI subjects do not fully confirm the positive results of some other association studies. Sentinelli et al. [18] failed to find any association between OLR1 3'-UTR 188 C > T polymorphism and susceptibility to CAD or CAD severity in an Italian population. Actually, as in our observation, the distribution of the candidate gene is characterized by many positive and negative results, so that all of these studies, including ourselves, do not provide conclusive evidence in favour or against this hypothetic genetic association. In the study by Sentinelli et al., the authors did not find any association between genotype IVS4-14 GG and other clinical and metabolic parameters (e.g. hypertension, diabetes mellitus, dyslipidaemia, total cholesterol, HDL, LDL, triglycerides, blood glucose). This is in contrast with our finding of an association between IVS414 GG genotype presence and the distribution of type 2 DM, microalbuminuria or elevated HOMA index. Actually, the authors have excluded patients with the diagnosis of diabetes mellitus from their control group so that they are not able to evaluate a possible relation between the expression of OLR1 genotype and an alteration of glycidic metabolism. On the other hand, it is well known the relationship between glucose metabolism alterations and expression of OLR1 genotype [5,26-28]. In several experimental conditions, it has been shown that glucose by itself is able to increase the expression of LOX-1, that is, in endothelial cells and macrophages, $[29,30]$ as well as in the aorta from diabetic compared to not diabetic rats [31]. More recently, Tan et al. [32] have shown in human beings both in vivo and in vitro that the serum levels of LOX1 are increased in patients with diabetes and decrease significantly after improvement in glycemic control. Furthermore, Chui et al. [33] demonstrated a critical role for LOX-1 in the regulation of adipocyte metabolism and, potentially, insulin sensitivity, by peroxisome proliferator-activated receptor $\gamma$ (PPAR $\gamma$ ) ligands. The positive association between LOX1 expression and diabetes as a potential cardiovascular risk factor is further confirmed in our study by results of HOMA index, and microalbuminuria. Actually, the latter is a consistent and independent risk factor for cardiovascular and renal disease in patients with diabetes and/or hypertension, and in the general population [34].

A number of evidence suggests the link between chronic inflammation and oxidative stress as the main mechanism responsible for endothelial dysfunction and cardiovascular complications in patients with MS $[1,23]$. The current study further seems to support the hypothesis that the enhanced systemic oxidative stress in patients with MS is associated with visceral adiposity and liver steatosis. It has to be underlined that in our experience, the assessment of TBARs concentrations accurately indicates the oxidative alterations of lipids and therefore we used this parameter together with the evaluation of thioredoxin levels to explore the oxidative stress. In fact, we show that the circulating lipid peroxidation products are higher in patients with MS and particularly in those with risk genotype and that relationships exist between the levels of the antioxidant thioredoxin and ALT and TBARs concentrations. This finding suggests that thioredoxin is actively involved in the process of endothelial preservation from oxidative damages in patients with MS and that its lower levels are associated with higher concentrations of lipid peroxidation products. The higher levels of thioredoxin in patients with MS may be interpreted as an adaptive measure to counteract oxidative stress. Thioredoxin is also active in regulating nitric oxide metabolism and nitrosothiols decomposition. The latter have been found to be decreased in patients with MS [23]. As a consequence, our results strengthen the idea that circulating thioredoxin serves to protect surface protein thiols from oxidation other than regulate nitrosothiol levels and vasodilation in these patients. Considering together the results on oxidative stress parameters, it appears that it is the combination of more constituent parameters determining the appearance of the MS more than the difference in LOX genotype to determine the occurrence of systemic oxidative stress in this group of patients.

In conclusion, even if the risk genotype GG frequency for the IVS4-14 A>G polymorphism of OLR 1 gene seems not to be significantly increased in subjects with MS, we found a significant association between the risk genotype GG, type 2 DM, insulin resistance and microalbuminuria, whose clinical importance needs to be confirmed in a wider population study, because our study involves a limited number of subjects in each recruited population.

\section{Acknowledgements}

We wish to thank Dr. Lino Renna, (Bouty Technogenetics, Milan, Italy) for his logistic support.

\section{Conflict of interest}

The authors state also that no financial or other relationships exist that might lead to a conflict of interest.

\section{Address}

Department of Biomedical Sciences and Human Oncology, Clinica Medica 'A. Murri', University of Bari, Bari, Italy (V. O. Palmieri, I. Grattagliano, G. Cardinale, P. Portincasa, G. Palasciano); Department of Clinical Pathology I, Policlinico 
University Hospital, Bari, Italy (B. Coppola, V. Casieri, F. Di Serio).

Correspondence to: Vincenzo O. Palmieri, MD, Department of Biomedical Sciences and Human Oncology, Clinica Medica 'A. Murri', University of Bari- Policlinico, 70124 Bari, Italy. Tel.: +39 080 5478707; fax: +39 080 5478778; e-mails: v.o.palmieri@gmail.com; v.palmieri@semeiotica.uniba.it

Received 22 April 2012; accepted 20 September 2012

\section{References}

1 Grattagliano I, Palmieri VO, Portincasa P, Moschetta A, Palasciano G. Oxidative stress-induced risk factors associated with the metabolic syndrome: a unifying hypothesis. J Nutr Biochem 2008;19:491-504.

2 Isomaa B, Henricsson M, Almgren P, Tuomi T, Taskinen MR, Groop L. Cardiovascular morbidity and mortality associated with the metabolic syndrome. Diabetes Care 2001;24:683-9.

3 McNeill AM, Rosamond WD, Girman CJ. The metabolic syndrome and 11- year risk of incident cardiovascular disease in the atherosclerosis risk in communities study. Diabetes Care 2005;28: 385-90.

4 Sawamura T, Kume N, Aoyama T, Moriwaki H, Hoshikawa H, Aiba $Y$ et al. An endothelial receptor for oxidized low-density lipoprotein. Nature 1997;386:73-7.

5 Mehta JL, Chen J, Hermonat PL, Romeo F, Novelli G. Lectin-like, oxidized low-density lipoprotein receptor-1 (LOX-1): a critical player in the development of atherosclerosis and related disorders. Cardiovasc Res 2006;69:36-45.

6 Chen M, Masaki T, Sawamura T. LOX-1, the receptor for oxidized low-density lipoprotein identified from endotelial cells: implications in endothelial dysfunction and atherosclerosis. Pharmacol Ther 2002;95:89-100.

7 Murphy JE, Tedbury PR, Homer-Vanniasinkam S. Biochemistry and cell biology of mammalian scavenger receptors. Atherosclerosis 2005;182:1-15.

8 Chen M, Kakutani M, Minami M, Kataoka H, Kume N, Narumiya S et al. Increased expression of lectin-like oxidized low density lipoprotein receptor-1 in initial atherosclerotic lesions of Watanabe heritable hyperlipidemic rabbits. Arterioscler Thromb Vasc Biol 2000;20:1107-15.

9 Li D, Williams V, Liu L, Chen H, Sawamura T, Antakli T et al. LOX1 inhibition in myocardial ischemia-reperfusion injury: modulation of MMP-1 and inflammation. Am J Physiol Heart Circ Physiol 2002;283:H1795-801.

10 Nagase M, Hirose S, Sawamura T, Masaki T, Fujita T. Enhanced expression of endothelial oxidized low density lipoprotein receptor (LOX-1) in hypertensive rats. Biochem Biophys Res Commun 1997;237:496-8.

11 Kume N, Murase T, Moriwaki H, Aoyama T, Sawamura T, Masaki T et al. Inducible expression of LOX-1, a novel lectin-like receptor for oxidized low density lipoprotein, in vascular endothelial cells. Circ Res 1998;83:322-7.

12 Chen M, Nagase M, Fujita T, Narumiya S, Masaki T, Sawamura T. Diabetes enhances lectin-like oxidized LDL receptor-1 (LOX-1) expression in the vascular endothelium: possible role of LOX-1 ligand and age. Biochem Biophys Res Commun 2001;87:962-8.
13 Aoyama T, Sawamura T, Furutani Y, Matsuoka R, Yoshida MC, Fujiwara $\mathrm{H}$ et al. Structure and chromosomal assignment of the human lectin-like oxidized low-density lipoprotein receptor 1 (LOX1) gene. Biochem J 1999;39:177-84.

14 Mango R, Clementi F, Borgiani P, Forleo GB, Federici M, Contino G et al. Association of single nucleotide polymorphisms in the oxidised LDL receptor 1 (OLR1) gene in patients with acute myocardial infarction. J Med Genet 2003;40:933-6.

15 Chen Q, Reis SE, Kammerer C, Craig WY, LaPierre SE, Zimmer EL et al. Genetic variation in lectin-like oxidized low-density lipoprotein receptor 1 (LOX1) gene and the risk of coronary artery disease. Circulation 2003;107:3146-51.

16 Mango R, Biocca S, Del VecchioF, Clementi F, Sangiuolo F, Amati F et al. In vivo and in vitro studies support that a new splicing isoform of OLR1 gene is protective against acute myocardial infarction. Circ Res 2005;97:152-8.

17 Trabetti E, Biscuola M, Cavallari U, Malerba G, Girelli D, Olivieri O et al. On the association of the oxidised LDL receptor 1 (OLR1) gene in patients with acute myocardial infarction or coronary artery disease. Eur J Hum Genet 2006;14:127-30.

18 Sentinelli F, Filippi E, Fallarino M, Romeo S, Fanelli M, Buzzetti R et al. The 3'-UTR C>T polymorphism of the oxidized LDL-receptor 1 (OLR1) gene does not associate with coronary artery disease in Italian CAD patients or with the severity of coronary disease. Nutr Metab Cardiovasc Dis 2006;16:345-52.

19 Vietri MT, Molinari AM, Boggia M, Parisi M, Cioffi M. IVS4-14 A/G and IVS4-73 C/T Polymorphisms in OLR1 Gene in Patients with Ischemic Cerebrovascular Diseases. Genet Test Molec Biomark 2010;14:9-11.

20 Vecchione L, Gargiul E, Borgiani P, Predazzi I, Mango R, Romeo F et al. Genotyping OLR1 gene: a genomic biomarker for cardiovascular diseases. Recent Patents Cardiovasc Drug Discov 2007;2:147-51.

21 National Institutes of Health. Third Report of the National Cholesterol Education Program Expert Panel on Detection, Evaluation, and Treatment of High Blood Cholesterol in Adults (Adult Treatment Panel III). Executive Summary. Bethesda, MD: National Institutes of Health, National Heart, Lung and Blood Institute, 2001 (NIH publ. no. 01-3670)

22 International Task Force for Prevention of Coronary Heart Disease (http://www.chd-taskforce.com/coronary_risk_assessment.html). Accessed on January 2012.

23 Palmieri VO, Grattagliano I, Portincasa P, Palasciano G. Systemic oxidative alterations are associated with visceral adiposity and liver steatosis in patients with metabolic syndrome. J Nutr 2006;136: 3022-6.

24 Grattagliano I, Portincasa P, Palmieri VO, Palasciano G. Mutual changes of thioredoxin and nitrosothiols during biliary cirrhosis: results from humans and cholestatic rats. Hepatology 2007;45:331-9.

25 Simera I, Moher D, Hoey J, Schulz KF, Altman DG. A catalogue of reporting guidelines for health research. Eur J Clin Invest 2010;40: 35-53.

26 Renier G. Lectin-like oxidized low-density lipoprotein receptor-1 (LOX-1), a relevant target for diabetic vasculopathy? Cardiovasc Hematol Disord Drug Targets 2008;8:203-11.

27 Renie G, Maingrette F, Li L. Diabetic vasculopathy and the lectinlike oxidized low-density lipoprotein receptor-1 (LOX-1). Curr Diabetes Rev 2007;3:103-10.

28 Musso G, Cassader M, De Michieli F, Saba F, Bo S, Gambino R. Effect of lectin-like oxidized LDL receptor-1 polymorphism on liver disease, glucose homeostasis, and postprandial lipoprotein 
metabolism in nonalcoholic steatohepatitis. Am J Clin Nutr 2011;94:1033-42.

29 Li L, Sawamura T, Renier G. Glucose enhances human macrophage LOX-1 expression: role for LOX-1 in glucose-induced macrophage foam cell formation. Circ Res 2004;94:892-901.

30 Li L, Sawamura T, Renier G. Glucose enhances endothelial LOX-1 expression: role for LOX-1 in glucose-induced human monocyte adhesion to endothelium. Diabetes 2003;52:1843-50.

31 Kita T, Kume N, Ishii K, Horiuchi H, Arai H, Yokode M. Oxidized LDL and expression of monocyte adhesion molecules. Diabetes Res Clin Pract 1999;45:123-6.
32 Tan KC, Shiu SW, Wong Y, Leng L, Bucala R. Soluble lectin-like oxidized low density lipoprotein receptor- 1 in type 2 diabetes mellitus. J Lipid Res 2008;49:1438-44.

33 Chui PC, Guan HP, Lehrke M, Lazar MA. PPARgamma regulates adipocyte cholesterol metabolism via oxidized LDL receptor 1. J Clin Invest 2005;115:2244-56.

34 Maione A, Nicolucci A, Craig JC, Tognoni G, Moschetta A, Palasciano G et al. Protocol of the Long-term Impact of RAS Inhibition on Cardiorenal Outcomes (LIRICO) randomized trial. J Nephrol 2007;20:646-55. 